IRA-International Journal of Education \& Multidisciplinary Studies ISSN 2455-2526; Vol.05, Issue 02 (2016)

Pg. no. 58-65

Institute of Research Advances http://research-advances.org/index.php/IJEMS

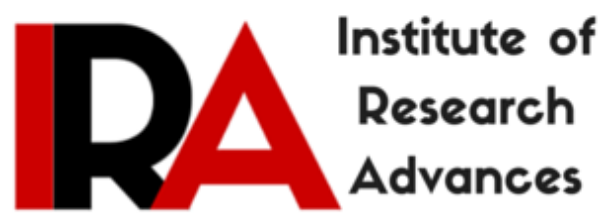

\title{
The Evaluation of Students' Procedural Knowledge Ability and Identifying, Analyzing, Classifying the Subject Matters of High School Physics Textbook in Tiered Task -1
}

\author{
Djeli Alvi Tulandi \\ Department of Physics Faculty of Science and Mathematic, \\ University of Manado, Indonesia.
}

Type of Review: Peer Reviewed.

DOI: http://dx.doi.org/10.21013/jems.v5.n2.p1

\section{How to cite this paper:}

Tulandi, D. (2016). The Evaluation of Students' Procedural Knowledge Ability and Identifying, Analyzing, Classifying the Subject Matters of High School Physics Textbook in Tiered Task -1. IRA International Journal of Education and Multidisciplinary Studies (ISSN 2455-2526), 5(2), 58-65. doi:http://dx.doi.org/10.21013/jems.v5.n2.p1

(C) Institute of Research Advances

(cc) EY-NC

This work is licensed under a Creative Commons Attribution-Non Commercial 4.0 International License subject to proper citation to the publication source of the work.

Disclaimer: The scholarly papers as reviewed and published by the Institute of Research Advances (IRA) are the views and opinions of their respective authors and are not the views or opinions of the IRA. The IRA disclaims of any harm or loss caused due to the published content to any party. 


ABSTRACT
Tiered task is a task that is given through strategic course with other courses that support
continuously at each semester. This study aims to evaluate the students' procedural knowledge ability
through the process of identifying, analyzing and classifying the physics textbook and the students'
achievement and perceptions where the tiered task -1 are given. This study uses the same subjects
design(treatment by subject). The subjects in this study are the third semester students of physics
education UNIMA of 68 students. All groups are treated and data derived from the study are the work
result in groups containing identification-analysis-classification format of the sub-topic of the
structure and characteristics of the book. Data analysis technique use quantitative descriptive in
percentage according to variables and use the average score of the group to see the achievement. The
results show that, at task I, the students are still not fully able to identify-analyze-classify the high
school physics textbook. Similarly, students have not understood the procedural knowledge
correctly. But at task II and III, there is increase of the students' ability to develop the textbook
related to map concepts, theories, law and principle concepts and also relates to the ability to develop
mathematical description, exercises, and summarizing. Barriers in doing the assignment are mainly
experienced by the students who are not serious in group discussion and less discuss with tutors. The
process of assigning the tiered task - 1 helps students to improve basic physics and be a provision in
continuing the tiered task tiered at The Study of Physics II course.

Keywords: Tiered Task-1, Textbook, Identification-Analysis-classification and procedural knowledge.

\section{Introduction}

The challenge of education world today requires readiness and professionalism of teachers in the doing their duties. Hence, the competence of teachers-candidates students should be the major concern in teacher education. The reality of education implementation in Physics education department, Manado State University (UNIMA) shows that the students' completion time of study and the mastery of competencies show considerable variation. For most of the students who spend their study for more than four years, their mastery of competencies as teacher candidates (material mastery, methods of evaluation and learning, and research) are classified as less. On the other hand, students who excel and engage in collaborative research with lecturers in general complete the study within four or less than four years (Medellu, 2011). The reflections on the implementation of the lecture show that the coursework of semester I to VII is detached, so it does not systematically support the comprehensive development of students' competence. Most students find it difficult to formulate a high quality and useful research materials.

Tiered task is a task that is given through strategic course. This task is designed to gradually build up the competence or the ability of the teaching profession for students, especially students of physics education. The design of tiered task is potential to combine and ensure the coherence of assignment for semester to semester, in building the profession experience of physics teacher. This will ensure the efficiency and productivity of learning (Tulandi, 2015).

The implementation of tiered task begins by giving the tiered task -1 for the third semester students in the strategic study of physics -1 course with a focus on improving basic knowledge of physics. Noah (2004) explains the importance of mastering the basic concepts of physics to study the further concept. The syllabus course of the study of physics -1 includes reviewing the material of high school physics textbook (junior and senior high school or equivalent). Generally, the subject matter of high school physics will be the object of students' research so that the mastery of high school physics is very necessary. The literature for high school physics can be obtained by students through the Internet or by buying textbooks on the market. To get an idea of the extent to which students are able to study the high school physics teaching materials, it needs to conduct the evaluation of physics learning materials developing process using some physics textbook by students in the study of physics -1 course where the tiered task -1 is given and evaluate the process of increasing mastery of 
procedural knowledge through the identification-analysis-classification and development of high school physics teaching materials, as well as evaluating the student's perception of the content and activities of the tiered task -1 .

Textbooks are books published and distributed by the government as a textbook in a particular field of study, which is the standard book and compiled by experts in that field for instructional purposes and objectives equipped with a means of teaching which is harmonious and easy to be understood by the users in schools thus it can support teaching programs. Susilawati and Khoiri (2006) explains that in the learning process, the presentation of instructional materials should be the core competencies of teachers in designing activities and the think ability that should be mastered by student. In teaching materials, teachers have confirmed the extent to which the preparedness level of students in achieving goals and learning experiences. To add the experience of students, teachers should always be active and creative in act their role as inspiring facilitator. Furthermore, National Education Standards Agency (BSNP, 2006) explains that learning science is not only oriented to the mastery of course content, but also required the mastery of the process and context of science. Musanni (2015) explains that physics was built based on scientific methods through the analysis of the facts thus becoming the concepts, principles, laws, and to the theory. Therefore, physics learning should follow scientific methods through the use of learning based on the discovery and Student-centered. In doing activities with the scientific methods, it needs procedural knowledge.

\section{Research and Methode}

This research is descriptive analytic in analyzing the process of developing the material, analyzing the process of improving the mastery of procedural knowledge through the identificationanalysis-classification process and the development of high school physics teaching materials, analyzing and describing the achievement, potential and barriers experienced by students in the development of the material by using the treatment by subject design. (Dimitrov \& Rumrill.2005 in Solang 2015).

The research is conducted at the Physical Education Study Program, Department of Physics, University of Manado, on September-December 2015 at students who contract. The Study of Physics I course, Physics Education.

The obtained data includes (1): The identifying and analyzing process of book contents using the check list containing indicators for assessment. The book contents are related to the laws, principles, theories, concepts maps, mathematical descriptions, procedural knowledge, and exercises. (2) The achievement of learning (doing tasks) is based on the task and the product portfolio, (3) The potential and constraints in doing tasks through the interview based on the identification of the advantages and disadvantages of task. The books that are used in this research are the books that are widely used in schools, i.e. High School Physics Textbook by Marthen Kanginan, Sri Handayani, Sunardi and Bambang Hariadi. The contents of the book are limited on the topics: Force, Work and Energy, Impulse Momentum and Fluid. 


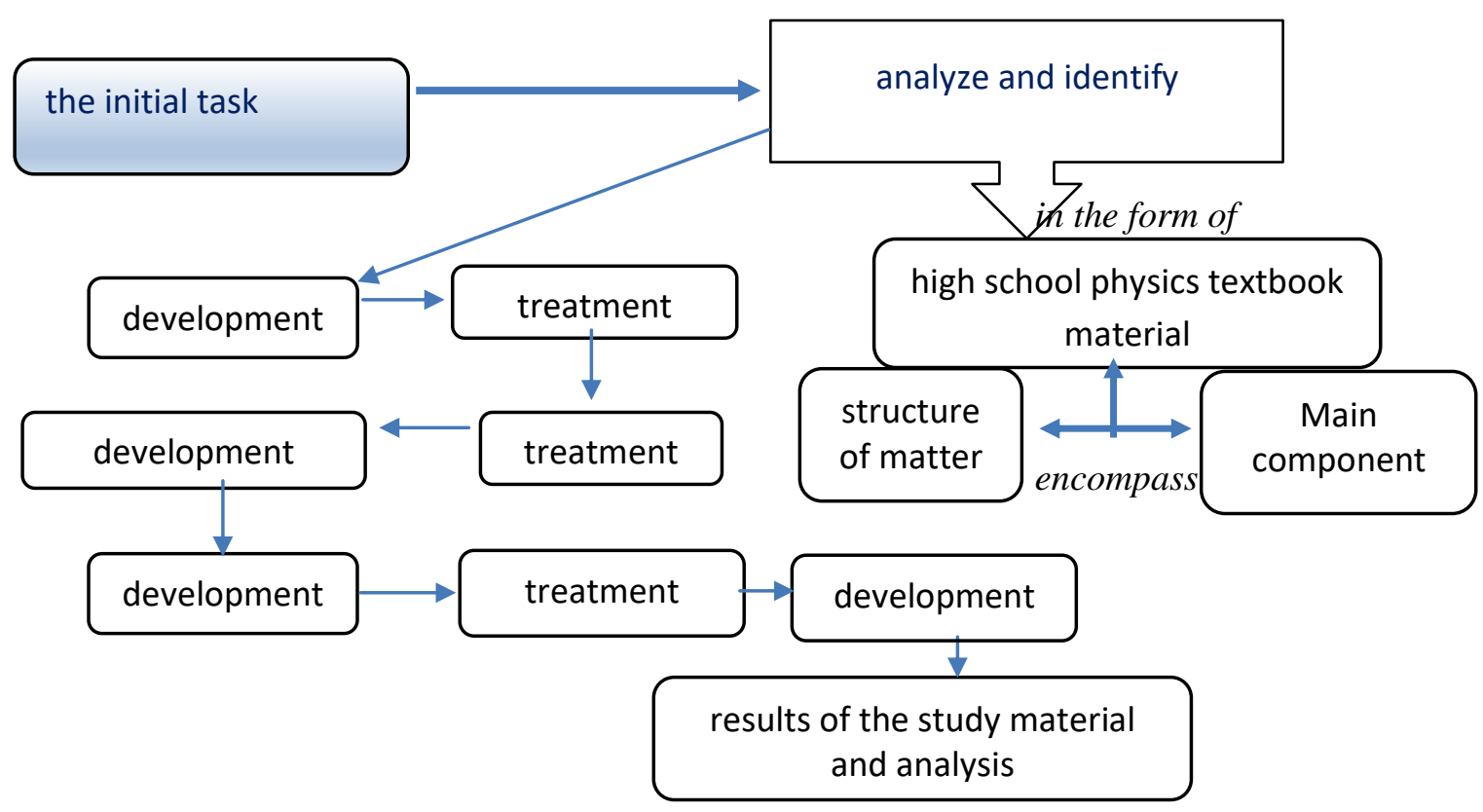

Figure-1. Research procedure

Descriptive analytical research: analyzing the process of identifying and analyzing materials by the students, and describing the achievement, potential and barriers by using the treatment by subject design (Dimitrov \& Rumrill 2005, in Solang 2015).

\section{Results and Discussion}

\section{A. Results}

Tasks are given to the subject of research to identify, classify and analyze. They do the work according to the stages and the filling in of forms. At Task I, They identify, classify and analyze the contents of the book related to concept maps, mathematical description, experimental procedures / observation, exercises, and summary. Furthermore, the task is checked by the researcher and the expert team and then returned and the students revise / complete and develop the content of the book. This activity lasts until the task III and the results are described in the following pictures.

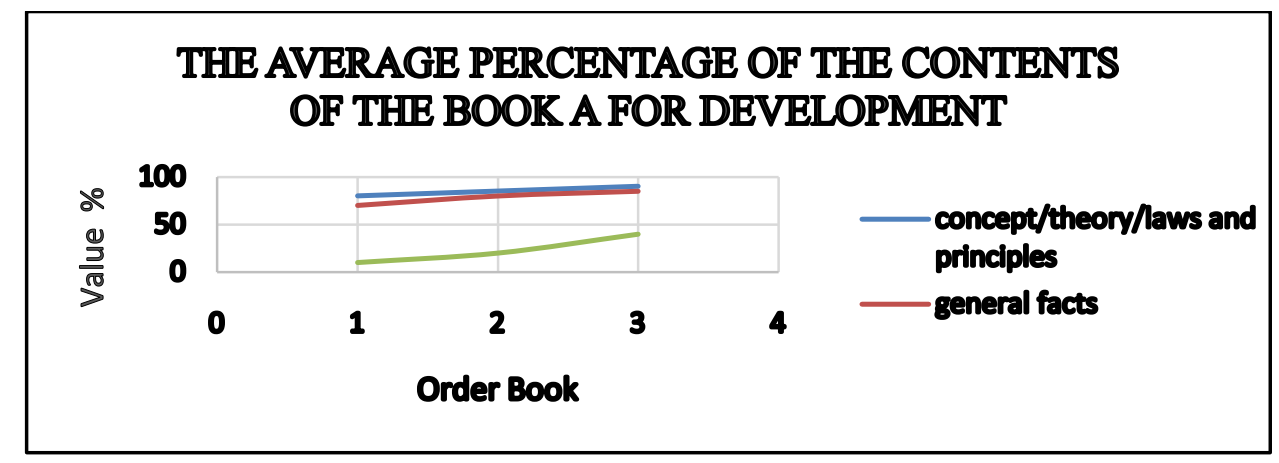

Figure-2. Graph material development tasks by the student group

Furthermore, given task related to the student's ability to complete / developing a concept map, a mathematical description, experimental procedures / observation, exercises and an overall summary of the results can be seen in Figure 3 below. 


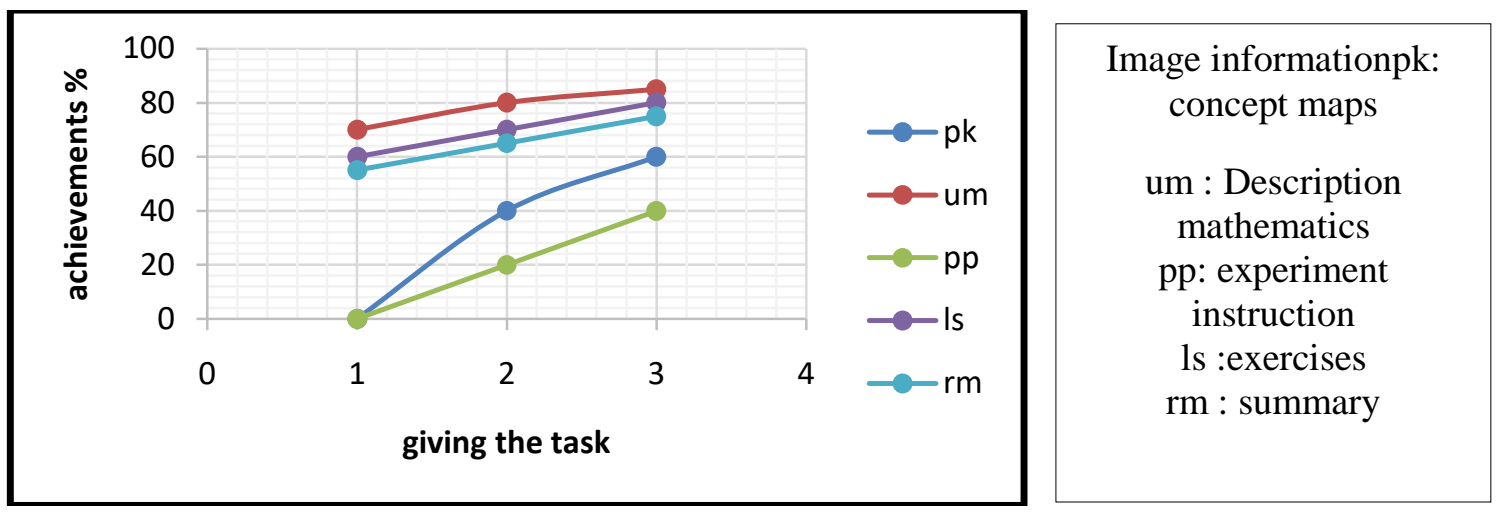

Figure-3. The average percentage of completeness of the materials development task group of students

Figure 4 below shows the value of the task group and its development for the topics: force, work and energy, impulse, momentum and fluids. Students discuss each of these materials in groups and fill the task form.

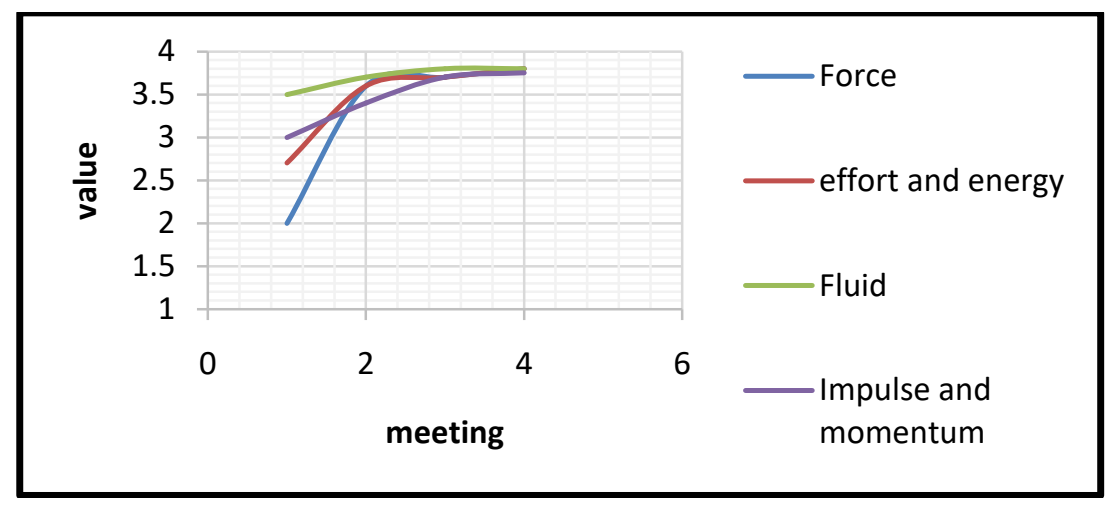

Figure-4. Values group assignments and material development process.

The following chart illustrates the development of individual work and group work in identifying, classifying and analyzing the procedural knowledge in high school physics textbooks.

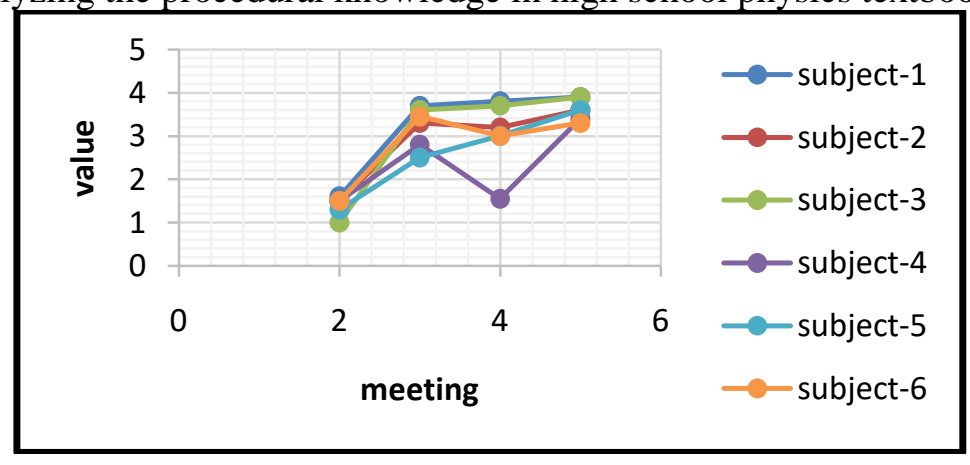

Figure -5 The development of procedural knowledge mastery of style materials 


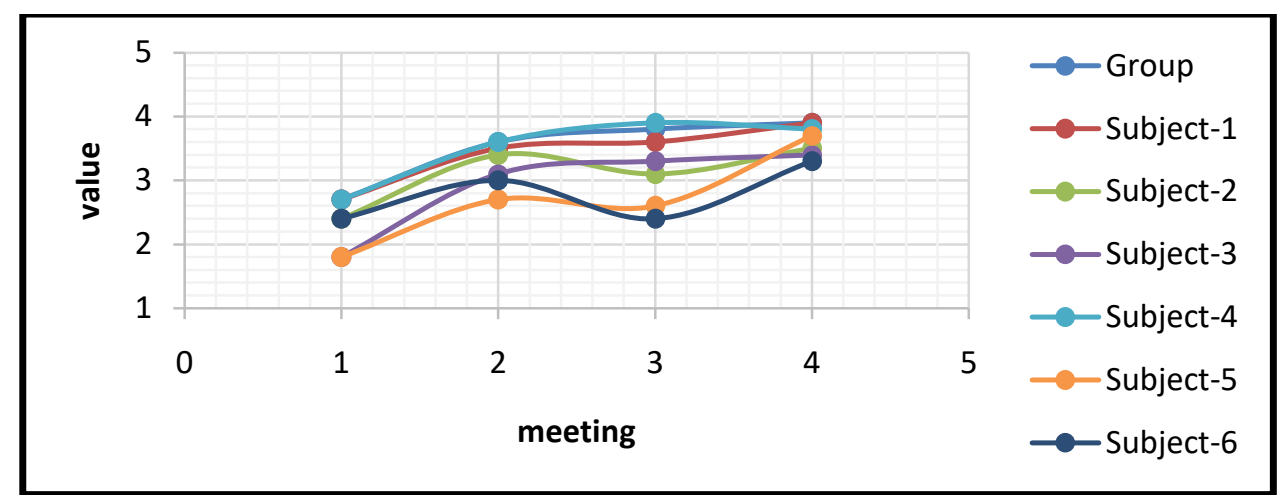

Figure -6 Procedural Knowledge Content Mastery development effort and energy

\section{The Evaluation of Students' Capability, Achievement and Constraints in Developing Content}

Based on the interview by the investigators to the students who participated in The Study of Physics I course wherein the tiered task -1 is given about the achievements and obstacles in developing the physics subject matters according to the material characteristics: (1) the concept/principle/theory/law, (2) procedures, (3) the common/global fact/phenomenon, (4) the local phenomenon/context. The most student groups have been able to develop physics subject matters well and get good grades from researchers. But in the process of developing the subject matter, students was experiencing barriers including: a group of students admit that they have not fully mastered the materials, student groups cannot distinguish between common / global fact / phenomenon with local context / phenomenon so that the groups are difficult in developing the material, lack of discussion among the group members, the task is done by the thought of one member of the group and no group has distributed the materials to each member of the group so that not all members of the group understand the whole subject matter.

\section{The Description of Students' Perceptions}

The description of students' perception can be known by the researchers through the interview stage with each group after the group develop the materials and finish the final product. The interview results are about the design of materials and lectures, the contribution of activities on the achievement of competence, contribution of materials and activities to increase the developing ability the subject matter of discussion according to the physics material characteristics (1 to 4), facilitation of learning and evaluation, the impact of learning activities on the ability to summary the tasks from various sources, making paper using multiple sources, the impact of activity on the learning type / pattern. Each group of students mostly give positive opinion about the activities of the subjects learned through the study of physics-1 course where there tiered task is given. Each group believes that the design of lecture materials and activities are good and can increase students' competence in developing physics teaching materials and produce good final product through the identificationanalysis-classification process, and also the group can learn to establish good communication with his fellow group members so also with lecturers / researchers and can build forms / patterns of good learning.

\section{B. Discussion}

The work assigning can also be interpreted as a way of presenting the lesson material by assigning work to students to be done outside school hours in a certain time span and the results must be accountable. The task is given if the student need to deepen the mastery of learning materials, and need to develop the material, wants to foster interest and sense of responsibility, also needs to improve the ability to produce something as a follow-up. The advantages of the assigning task method can encourage students' initiative, fostering students' interests and responsibilities, and can improve the quality of learning results.

The results show that students who participate in The Study of Physics -1 course where the tiered task -1 is given are not fully able to identify-analyze-classifying the content of the textbook of 
physics with different authors, not fully able to identify-analyze-classify the range of material, the main components and the physical characteristics: (1) the concept / principle / theory / law, (2) procedures, (3) common / global the fact / phenomenon, (4) the local phenomenon / context. Data obtained from the identification-analysis-classification process of the material structure of books and the main component of the book (flowcharts, mathematics component, physics component, exercises and summary).There are groups that have the same understanding with the researchers in identifying, analyzing and classifying the contents of the textbook because of the scores given by the groups are same with the scores given by the researchers, but there are also groups that have a different understanding by researchers because of the scores given by groups are different with investigators. After the students pay attention to the advice and guidance from the researchers and expert teams, they can gradually understand and become fast in filling the tasks format.

Figure 1 the research results above provide information that the identification and classification of the laws, concepts, theories and principles in force, work, energy and fluids topics continue to improve during the three meetings after the remedial treatment is given. Similarly, there is an improvement in understanding of the common facts and the local context in high school physics textbooks. Figure 2 above shows how the students can identify and classify and also analyze the concept maps, mathematical description, experimental procedures, exercises and summary of the high school physics textbooks. By giving feedback (remedial treatment at task I, the student can fix the shortcomings and so on at the meeting III the students get better results. It is recorded also from the analysis result of the students that the content of the local context in textbooks is still lack and this is simply because the authors generally present their theory from the general facts. In doing / filling the assigned task format, students do individually or in groups. The figure 3 gives an explanation that doing in group results is better than doing individually. Mina and Miranda (2010) explain that the involvement in cooperative learning will provide a powerful learning experience for students.Furthermore, Maryellen (2010) says that the collaborative evaluation can motivate students to complete the task and be able to develop a positive attitude inter-peers. Working individually is very dependent on the ability of each individual so that the results are very varied as shown in Figure4.5. According to Wasley (2006)\&Alison (2011),students who participate in learning activities and educational collaborative outside the classroom and more interact with fellow members will get better grades, are more satisfied with their education, and more likely to remain in college. The collaborative learning is a strategy in which students learn in small groups where they interact in their groups and learn from each other's experiences. The advantages of collaborative learning is by working together, the members of the small groups are able to overcome obstacles, to act independently and responsibly, to rely on the talents of the team, to trust others, to talk, and to make decisions.

The procedural knowledge related to the scientific methods in laboratories as well as conducting observations in nature is depend on the material characteristics so that the development pattern of students' understanding on the procedural knowledge such as the Figure 3, Figure 4 and Figure 5 which are also varied. Based on the interview results by the researchers to the education physics students who attend the Study of School Physics -1 which the tiered task -1 is given, the students' opinion regarding the activities of this tiered task -1 is the design of the lecture materials and activities is good and can increase the students' competence in developing physics teaching materials and produce a good final product through the identification-analysis-classification process, and also the group can learn to establish good communication with their fellow group members as well as with lecturers / researchers and can build good forms / patterns of learning. The final results show that the third semester students have been able to identify, classify and analyze the high school physics textbooks relating to components of laws, theories, concepts and principles as well as local and general facts, also the contents of the book related to concept maps, mathematical description, exercises and summaries. Through the remedial process done by the students on the completeness of the textbook according to the stages of research, it shows that students more know and understand the content of high school physics textbooks which will certainly help them doing their research later. It is also very helpful for the prospective teachers in performing their duties as teachers and physical education. Students as professional teacher candidates are deemed to master the teaching materials and organize strategies in teaching the materials to the students. 


\section{Recommendations}

The high school physics textbook on the market still needs to be enriched / including the related concept maps, local context and procedural knowledge. The group learning strategy allows the interaction between members so that it can happen to share experience and knowledge as well as to minimize the differences between group members and motivate peers to accomplish the given task. Giving tiered task in lectures in the department of education physics, UNIMA / teacher education institutions may be considered as a pattern of lecture.

\section{References}

Alison Burke, 2011. Group Work: How to Use Groups Effectively Southern Oregon University, Ashland, OR 97520The Journal of Effective Teaching, Vol. 11, No. 2, 2011, 87-95

BSNP. 2006. Permendiknas No. 22 of 2006 on the Content Standards for Primary and Secondary education units. Jakarta

Maryellen W.2007.Effective Group Work Strategies for the College Classroom. The teaching professor. Magna publication

Medellu,2011. Evaluation of the implementation of tiered task model developed through the project I'MHERE in the education department of physics, mathematics and chemistry education, in 2011

Mina T,Miranda.B.2010. A case study of cooperative learning and communication pedagogy. Journal of the Scholarship of Teaching and Learning, Vol. 10, No. 2, June 2010, pp. 78 - 89.

Musanni. 2015. Development of Teaching Materials Physics School, Based Learning Cycle (Lc) 3e On the Subject Matter Kinetic Theory of Gases and Thermodynamics. Journal of Science Education.

Noah F. 2004. Learning physics in context: a study of student learning about electricity and magnetism. Department of Physics University of Colorado, Boulder noah.finkelstein@ colorado.edu

Susilawati, Nur Khoiri.2006.Development of Teaching Materials Physics, Charged lifeskill for High School Students. Indonesian Journal of Physics, 18 (54), December 2014 ISSN: 1410-2994

Solang, N. 2015. Effectiveness of Problem Based Learning Physics, Using Simulation / Animation to Enhance Student Learning Outcomes. Skripsi. Tondano: Department of Physics, Faculty of Mathematics and Natural Sciences, State University of Manado

Tulandi,D.2015.Model tiered task to improve efficiency, productivity and quality of the process of formation of competence, student of physical education, FMIPA UNIMA. The research report featured grant colleges.

Wasley, P. 2006. Underrepresented students benefit most from 'engagement.' The Chronicle of Higher Education, 53 (13), p.39. 